Delft University of Technology

\title{
Third Party Risk Indicators and Their Use in Safety Regulations for UAS Operations
}

Jiang, C.; Blom, H.A.P.; Sharpanskykh, Alexei

DOI

10.2514/6.2020-2901

Publication date

2020

Document Version

Accepted author manuscript

Published in

AIAA AVIATION 2020 FORUM

\section{Citation (APA)}

Jiang, C., Blom, H. A. P., \& Sharpanskykh, A. (2020). Third Party Risk Indicators and Their Use in Safety Regulations for UAS Operations. In AIAA AVIATION 2020 FORUM [AIAA 2020-2901] (AIAA AVIATION 2020 FORUM; Vol. 1 PartF). https://doi.org/10.2514/6.2020-2901

\section{Important note}

To cite this publication, please use the final published version (if applicable).

Please check the document version above.

\section{Copyright}

Other than for strictly personal use, it is not permitted to download, forward or distribute the text or part of it, without the consent of the author(s) and/or copyright holder(s), unless the work is under an open content license such as Creative Commons.

\section{Takedown policy}

Please contact us and provide details if you believe this document breaches copyrights.

We will remove access to the work immediately and investigate your claim. 


\title{
Third Party Risk Indicators and Their Use in Safety Regulations for UAS Operations
}

\author{
Chengpeng Jiang ${ }^{1}$, Henk A.P. Blom ${ }^{2}$ and \\ Alexei Sharpanskykh ${ }^{3}$ \\ Delft University of Technology, Kluyverweg 1, 2629 HS Delft, The Netherlands
}

Use of Unmanned Aircraft Systems (UAS) is growing rapidly around the world. Very different types of UAS are used for applications such as aerial photography, inspection, emergency and Urban Air Mobility (UAM), operating in low altitude and urban environment, as well as in high altitude airspace integrated with the conventional air transportation system. As a new airspace user, UAS brings novel safety challenges to the current aviation system. For current aviation the main safety issues concern first and second parties, i.e. lives and property of crew and passengers. In contrast, the main safety concern of UAS operations is third party risk (TPR), i.e. the risk posed to people and properties that have no responsibility for the UAS operation and neither benefit in some way from the UAS operation. In order to ensure the safe operation of UAS, there is a need for an evaluation of safety regulation developments for UAS operations against relevant TPR indicators. The aim of this paper is to identify relevant TPR indicators for UAS operations and to evaluate safety regulations against these TPR indicators. The main finding is that current UAS safety regulations do not consider the accumulation of TPR contributions from many UAS flights per annum over rural or urban populations.

\section{Nomenclature}

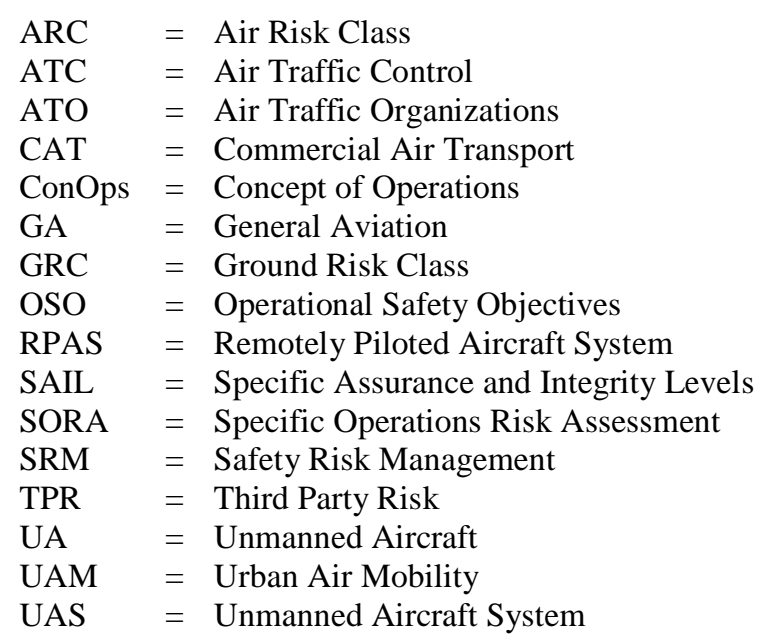

\footnotetext{
${ }^{1}$ Ph.D. Candidate, Section Air Transport and Operation, Faculty of Aerospace Engineering, Delft University of Technology, Kluyverweg 1, 2629 HS Delft, The Netherlands.

${ }^{2}$ Full Professor, Section Air Transport and Operation, Faculty of Aerospace Engineering, Delft University of Technology, Kluyverweg 1, 2629 HS Delft, The Netherlands.

${ }^{3}$ Assistant Professor, Section Air Transport and Operation, Faculty of Aerospace Engineering, Delft University of Technology, Kluyverweg 1, 2629 HS Delft, The Netherlands.
} 


\section{Introduction}

Unmanned Aircraft System (UAS) - including Remotely Piloted Aircraft System (RPAS) and automated air vehicles - are increasingly becoming a part of our day-to-day lives. The major driver of this development is that UAS can be employed for novel operations - e.g. recreation, aerial photography, emergency, inspection, urban air transport, long distance cargo transport - both in low altitude and urban environment, as well as in high altitude airspace integrated with the current air transportation system. Depending on the design, UAS can range from a small unit to the size of a small aircraft. Having UAS as part of daily operations is getting closer to reality as the immense effort has been put into developing UAS Concept of Operations (ConOps), rules, regulations and supporting infrastructures that are crucial to a safe operation [1].

The current aviation system has become so safe due to the contributions of many factors such as initial airworthiness (design, manufacturing quality), continuing airworthiness (maintenance) and operational approvals, Air Traffic Management (ATM), airborne safety nets, cockpit automation, etc. Moreover, an overarching factor is that all this has been reached thanks to decades of evolutionary developments that benefitted from feedback from experience and the diligent application of lessons learned from safety events. The introduction of UAS brings uncertainties into the system, with a large number of flights, of different types and sizes for various tasks, and with performance envelopes greatly different from those for which today's air traffic procedures were designed [1].

For current aviation the main safety issues concern first and second parties, i.e. lives and property of crew and passengers. In contrast, the main safety concern of UAS operations is third party risk (TPR), i.e. the risk posed to people and properties that have no responsibility for a UAS flight and neither benefit in some way from a UAS flight. In order to ensure the safe operation of UAS, there is a need to identify relevant TPR indicators for UAS operations and to evaluate safety regulation for UAS operations against these TPR indicators. An early study of this type has been conducted by [2], however significant UAS regulations updates have been developed since then [3]. The aim of this paper is to develop relevant TPR indicators for UAS operations and to compare EASA/JARUS and FAA safety regulations against these TPR indicators.

The paper is organized as follows. Section III reviews existing TPR indicators, and use this to define relevant TPR indicators for UAS operations. Section IV reviews the safety regulations from EASA/JARUS and FAA. Section V evaluates these regulations against the relevant TPR indicators identified in section III. Section VI draws conclusions.

\section{Relevant TPR Indicators}

This section starts with a review of relevant TPR indicators in use for commercial aviation. Subsequently these indicators are used as a basis for the definition of relevant TPR indicators for UAS operations. This approach differs from a straightforward application of TPR indicators in commercial aviation to UAS operation, e.g. [2].

\section{A. TPR indicators in commercial aviation}

In commercial aviation [4] first party is the aviation personnel (who provide the air transportation service); second party are the passengers (for whom the air transportation is provided); third party are the people exposed for reasons unrelated to the flight, for instance people living in the airport vicinity. Common indicators for TPR in commercial aviation are Individual Risk, Collective Risk and the so-called FN curve for societal risk, e.g. [5, 6].

Individual risk $R_{I}(s)$ of commercial air transport is defined as: "The probability that an average unprotected person, who resides permanently at ground location $s$, would get killed due to the direct consequences of an aircraft accident during a given annum. ” It should be noted that the Individual risk indicator is population-independent, i.e. it does not make any difference if a ground location $s$ is in a wasteland or in the center of a large city. Individual risk defines iso-risk contours that can be used for zonal policies regarding any current or future use of an (urban) area that is exposed to non-negligible Individual risk levels. For example, in The Netherlands the maximum acceptable level of $R_{I}(s)$ is $10^{-6}$ per annum for populated areas around hazardous installations, transport routes and airports [7].

Collective risk $R_{C}$ is the expected number of third party fatalities $R_{C}=E\left\{n_{F}\right\}$ in a given area $X$ due to the direct consequences of aircraft flight accidents during a given annum [8]. If there are $N$ flights to happen in a given annum then we know [9]:

$$
R_{C}=E\left\{n_{F}\right\}=\sum_{i=1}^{N} E\left\{n_{F}^{i}\right\}=\sum_{i=1}^{N} R_{C}^{i}
$$

with $R_{C}^{i}=E\left\{n_{F}^{i}\right\}$ the expected number of third party fatalities due to a potential accident of the $i$-th flight.

In commercial aviation, another well-established societal risk indicator is the FN curve $R_{F N}(n)$ :

$$
R_{F N}(n) \triangleq P\left\{n_{F} \geq n\right\}, \text { for } n \geq 1
$$


which reads in words, e.g. [9]: "The probability that a group of n or more third party persons will be fatally injured due to the direct consequences of an aircraft accident during a given annum."

Some literature sources, e.g. [5] refer to "more than $n$ " in this definition, which defines $R_{F N}^{>}(n)$ as follows:

$$
R_{F N}^{>}(n) \triangleq P\left\{n_{F}>n\right\}=R_{F N}(n+1), \text { for } n \geq 0
$$

The relation between the FN curve $R_{F N}(n)$ and collective risk $R_{C}=E\left\{n_{F}\right\}$ has been well established, e.g. [9]:

$$
R_{C}=E\left\{n_{F}\right\}=\sum_{n=1}^{\infty} R_{F N}(n)=\sum_{n=0}^{\infty} R_{F N}^{>}(n)
$$

[5] explain that the FN curve $R_{F N}(n)$ is used in various countries to express and limit third party risks, predominantly of hazardous installations. Regulation in these countries typically adopts an $R_{F N}(n)$ limiting criterion of the following form:

$$
R_{F N}(n)<C / n^{\alpha}
$$

where $\alpha$ is the steepness of the limit line and $C$ a constant that determines the position of the limit line. A steepness $\alpha=1$ is called risk neutral (e.g. in UK); a steepness $\alpha=2$ is called risk averse (e.g. in the Netherlands). In the latter case larger accidents are weighted more heavily and are thus only accepted with a relatively lower probability. The different views regarding risk aversion parameter $\alpha$ make $R_{F N}(n)$ less useful as a common risk indicator than Collective risk $R_{C}=E\left\{n_{F}\right\}[10]$.

\section{B. TPR indicators for UAS}

For UAS operations, risks involved with first, second and third parties are defined as follows [11]. First party risk applies to people and property directly associated with the UAS operation (e.g. pilot, Unmanned Aircraft itself). Second party risk applies to people and property not associated with the UAS operation, but directly derive benefit from the UAS operation (e.g. passenger on-board, infrastructure being inspected, parcel being delivered). Third party risk applies to people and property not associated with, nor deriving direct benefit from the UAS operation.

By comparing this definition of first, second and third parties with those in commercial aviation, some differences can be observed. Although these differences may look futile at first impression, they do have significant consequences. To make this explicit let's compare first, second and third party fatalities for the following two mid-air collisions: i) mid-air between two commercial aircraft; vs. ii) mid-air of a UAS to a commercial aircraft. In case i), first party fatalities may be among the crew of the two aircraft, second party fatalities may be among the passengers on-board the two aircraft, and third party fatalities may be among persons on the ground if one or both aircraft crash to the ground. In case ii) there typically are no first or second party fatalities for the UAS operation; instead all on-board fatalities among crew and passengers of the commercial flight are third party fatalities, which add to fatalities on the ground if the UAS and/or the commercial aircraft crash to the ground. These significant differences in third party fatalities for these two cases, illustrate the need to explicitly define TPR indicators for UAS operations.

For a commercial UAS operation involving many flights we define the following three TPR indicators: Collective risk, Collective ground risk, and Individual risk as follows:

Collective risk $R_{C}$ of UAS operations is defined as: "The expected number of third party fatalities in a given area $X$ due to the direct consequences of UA flight accidents during a given annum."

Collective ground risk $R_{\text {Cground }}$ of UAS operations is defined as: "The expected number of third party fatalities on the ground in a given area $X$ due to the direct consequences of UA flight accidents during a given annum."

Individual risk $R_{I}(s)$ of UAS operations is defined as: "The probability that an average unprotected person, who resides permanently at ground location $s$, would get killed or fatally injured due to the direct consequences of UA flight accidents during a given annum."

For each of these TPR indicators we denote the contribution by the $i$-th UA flight as $R_{C}^{i}, R_{C g r o u n d}^{i}$, and $R_{I}^{i}(s)$ respectively. Hence for an UAS operation that conducts $N$ UA flights per annum, we have:

$$
\begin{gathered}
R_{C}=\sum_{i=1}^{N} R_{C}^{i} \\
R_{\text {Cground }}=\sum_{i=1}^{N} R_{\text {Cground }}^{i}
\end{gathered}
$$


If there are many UAS flights per annum, then the probability of a person at loaction $s$ missed by all UAS flights per annum equals the product over the miss probabilities of all UAS flights. Hence, the probability $R_{I}(s)$ that an Unprotected average person, who resides permanently at location $s$, is per annum not killed nor fatally injured due to the direct consequences of one of the $N$ UA flights satisfies:

$$
R_{I}(s)=1-\prod_{i=1}^{N}\left[1-R_{I}^{i}(s)\right]
$$

To characterize the relation between Collective risk $R_{C}$ and Collective ground risk $R_{C g r o u n d}$, one should notice that the following five types of UAS accidents have the potential of third party fatalities:

- $\quad$ Type 1: $i$-th UA flight collides to a commercial air transport (CAT) flight;

- $\quad$ Type 2: $i$-th UA flight collides to a general aviation (GA) flight;

- Type 3: $i$-th UA flight collides to an urban air mobility (UAM) UA carrying on-board passenger(s);

- Type 4: $i$-th UA flight collides to the ground as a consequence of a mid-air collision of types 1-3 or with another UA flight.

- Type 5: $i$-th UA flight collides to the ground without preceding mid-air collision.

Hence the Collective risk of the i-th UAS flight, $R_{C}^{i}$, satisfies the following sum of five terms:

$$
R_{C}^{i}=E\left\{n_{F}^{i}\right\}=E\left\{n_{F_{C A T}}^{i}\right\}+E\left\{n_{F_{G A}}^{i}\right\}+E\left\{n_{F_{U A M}}^{i}\right\}+E\left\{n_{F_{U A S a i r}}^{i}\right\}+E\left\{n_{F_{U A S g r o u n d}}^{i}\right\}
$$

where $E\left\{n_{F_{C A T}}^{i}\right\}$ denotes the expected number of on-board and ground fatalities at the side of a CAT flight due to a collision of type 1, $E\left\{n_{F_{G A}}^{i}\right\}$ denotes the expected number of on-board and ground fatalities at the side of a GA flight due to a collision of type 2, $E\left\{n_{F_{U A M}}^{i}\right\}$ denotes the expected number of on-board and ground fatalities at the side of a UAM flight due to a collision of type $3, E\left\{n_{F_{U A S a i r}}^{i}\right\}$ denotes the expected number of fatalities on the ground due to a collision of type 4, and $E\left\{n_{F_{U A S B r o u n d}}^{i}\right\}$ denotes the expected number of fatalities on the ground due a collision of type 5 . For Collective risk $R_{C}$ of a UAS operation involving $N$ UAS flights per annum the above means:

$$
R_{C}=E\left\{n_{F}\right\}=\sum_{i=1}^{N}\left[E\left\{n_{F_{C A T}}^{i}\right\}+E\left\{n_{F_{G A}}^{i}\right\}+E\left\{n_{F_{U A M}}^{i}\right\}+E\left\{n_{F_{U A S a i r}}^{i}\right\}+E\left\{n_{F_{U A S g r o u n d}}^{i}\right\}\right]
$$

Furthermore, each of the expected number of third party fatalities at the side of CAT, GA and UAM due to a collision with the i-th UA flight can be written as a sum of onboard fatalities and fatalities on the ground, i.e.

$$
\begin{aligned}
& E\left\{n_{F_{C A T}}^{i}\right\}=E\left\{n_{F_{C A T \text { onboard }}}^{i}\right\}+E\left\{n_{F_{C A T g r o u n d}}^{i}\right\} \\
& E\left\{n_{F_{G A}}^{i}\right\}=E\left\{n_{F_{\text {GAnboard }}}^{i}\right\}+E\left\{n_{F_{\text {GAground }}}^{i}\right\} \\
& E\left\{n_{F_{\text {UAM }}}^{i}\right\}=E\left\{n_{F_{\text {UAMonboard }}}^{i}\right\}+E\left\{n_{F_{\text {UAM ground }}}^{i}\right\}
\end{aligned}
$$

For Collective ground risk of the i-th UA flight, $R_{\text {Cground }}^{i}$, this means:

$$
R_{C g \text { round }}^{i}=\left[E\left\{n_{F_{C A T T_{\text {round }}}^{i}}^{i}\right\}+E\left\{n_{F_{\text {GAground }}}^{i}\right\}+E\left\{n_{F_{U A M g r o u n d}}^{i}\right\}+E\left\{n_{F_{U A S \text { air }}}^{i}\right\}+E\left\{n_{F_{U A S \text { ground }}}^{i}\right\}\right]
$$

Similarly, Collective ground risk $R_{\text {Cground }}$ of a UAS operation involving $N$ UAS flights per annum satisfies:

$$
R_{\text {Cground }}=\sum_{i=1}^{N}\left[E\left\{n_{F_{C A T_{g} \text { round }}}^{i}\right\}+E\left\{n_{F_{\text {GAground }}}^{i}\right\}+E\left\{n_{F_{\text {UAMground }}}^{i}\right\}+E\left\{n_{F_{U A S \text { Sair }}}^{i}\right\}+E\left\{n_{F_{\text {UAS r round }}}^{i}\right\}\right]
$$

\section{UAS Safety Management Frameworks}

This section evaluates the UAS safety management frameworks from EASA/JARUS and from FAA.

\section{A. EASA/JARUS UAS Safety Management Frameworks}

EASA and JARUS developed a regulatory concept introducing three risk categories for UAS, which are Open, Specific, and Certified [12, 13].

- Open category represents very low risk UAS operations requiring no involvement of aviation authorities;

- Specific category UAS presents a limited risk to people and property requiring risk mitigation, depending on the type of operation and nature of the risk, airworthiness requirement may be included; 
- Certified category UAS is regulated following the traditional approach to conventional aircraft, including type certification and compliance to airworthiness requirement.

Different regulation limitations and requirements between Open, Specific and Certified UAS operations [14, 15] are shown in Table 1. The Open category is divided into three subcategories A1, A2 and A3 with different operational limitations and technical requirements. Specific UAS operations are required to obtain an operational authorisation where the above requirements for Open category are not met, and the operator shall perform a risk assessment and submit to a competent authority. Certified category operations are conducted with relatively high risk (e.g. flying over assemblies of people, carrying people or dangerous goods, etc.) or when the competent authority, based on the risk assessment by the operator, considers the risk cannot be adequately mitigated.

Table 1. Characteristics of Open, Specific and Certified UAS Operations [14, 15]

\begin{tabular}{|c|c|c|c|c|c|c|}
\hline Category & \multicolumn{3}{|c|}{ Open } & \multirow{2}{*}{\multicolumn{2}{|c|}{$\begin{array}{c}\text { Specific } \\
\text { N/A } \\
\end{array}$}} & Certified \\
\hline Sub-category & A1 & A2 & A3 & & & N/A \\
\hline Class & $\mathrm{CO} / \mathrm{C} 1$ & $\mathrm{C} 2$ & $\mathrm{C} 2$ / C3 / C4 & \multicolumn{2}{|c|}{$\mathrm{N} / \mathrm{A}$} & $\mathrm{N} / \mathrm{A}$ \\
\hline MTOW & $<900 g$ & $<4 \mathrm{~kg}$ & $<25 \mathrm{~kg}$ & \multicolumn{2}{|c|}{$\mathrm{N} / \mathrm{A}$} & $\mathrm{N} / \mathrm{A}$ \\
\hline Flying altitude & $<=120 m$ & $<=120 \mathrm{~m}$ & $<=120 m$ & \multicolumn{2}{|c|}{$<=120 \mathrm{~m}$} & $\mathrm{~N} / \mathrm{A}$ \\
\hline Range & VLOS & VLOS & VLOS & \multicolumn{2}{|c|}{ VLOS/BVLOS } & VLOS/BVLOS \\
\hline $\begin{array}{c}\text { Autonomous } \\
\text { level }\end{array}$ & \multicolumn{3}{|c|}{ Manually } & \multicolumn{2}{|c|}{ Manually/Autonomous } & Manually/Autonomous \\
\hline $\begin{array}{l}\text { Over assemblies } \\
\text { of people }\end{array}$ & Not allowed & Not allowed & Not allowed & \multicolumn{2}{|c|}{ Not allowed } & Allowed \\
\hline $\begin{array}{l}\text { Over uninvolved } \\
\text { person }\end{array}$ & $\begin{array}{l}\mathrm{CO}(<250 \mathrm{~g} \\
<19 \mathrm{~m} / \mathrm{s})\end{array}$ & $\begin{array}{l}30 \mathrm{~m} \text { away or } \\
5 \mathrm{~m} \text { away in } \\
\text { low speed } \\
\text { mode }(<3 \mathrm{~m} / \mathrm{s})\end{array}$ & $\begin{array}{l}\text { 150m from } \\
\text { residential, } \\
\text { commercial, } \\
\text { industrial, } \\
\text { recreational } \\
\text { area } \\
\end{array}$ & Allowed & $\begin{array}{l}\text { Not } \\
\text { allowed }\end{array}$ & Allowed \\
\hline $\begin{array}{l}\text { Risk assessment } \\
\text { requirement }\end{array}$ & \multicolumn{3}{|c|}{ Not required } & \multicolumn{2}{|c|}{$\begin{array}{c}\text { Risk assessment } \\
\text { conducted by operator/ } \\
\text { Hold of LUC (Light UAS } \\
\text { operator certificate) }\end{array}$} & $\begin{array}{l}\text { Required, RPAS.1309 [13] } \\
\text { applies }\end{array}$ \\
\hline $\begin{array}{l}\text { Authorisation/ } \\
\text { certification } \\
\text { requirement }\end{array}$ & $\begin{array}{c}\text { Online } \\
\text { examination } \\
\text { of the } \\
\text { operator } \\
\end{array}$ & $\begin{array}{l}\text { Certificate of } \\
\text { remote pilot } \\
\text { competency }\end{array}$ & $\begin{array}{l}\text { Certificate of } \\
\text { remote pilot } \\
\text { competency }\end{array}$ & \multicolumn{2}{|c|}{$\begin{array}{l}\text { Application for } \\
\text { operational } \\
\text { authorisation }\end{array}$} & $\begin{array}{l}\text { Certificate of design, } \\
\text { production and } \\
\text { maintenance }\end{array}$ \\
\hline Size & \multicolumn{3}{|c|}{$<3 m$ (C3 UAS operation) } & $<=1 \mathrm{~m}$ & $<=3 \mathrm{~m}$ & No requirement \\
\hline Airspace & \multicolumn{3}{|c|}{ Uncontrolled } & \multicolumn{2}{|c|}{$\begin{array}{c}\text { Uncontrolled/ } \\
\text { Controlled } \\
\text { ( coordination required) }\end{array}$} & Uncontrolled/controlled \\
\hline Transportation & \multicolumn{5}{|c|}{ No transportation of people or dangerous goods } & $\begin{array}{l}\text { Allowed for transportation } \\
\text { of people/dangerous goods }\end{array}$ \\
\hline
\end{tabular}

SORA Method for Specific category

For Specific category UAS operations, JARUS developed the SORA (Specific Operations Risk Assessment) method $[16,17]$ to support the application for authorization. [17] explains the risk assessment aim of SORA through the three quantitative equations that are shown in Fig. 1. The $1^{\text {st }}$ and $3^{\text {rd }}$ equations capture fatality and economic risks respectively posed to third parties on the ground. The $2^{\text {nd }}$ equation captures fatality risk to third parties on-board manned aircraft. [17] also explains that it would not be realistic to conduct a quantitative risk assessment for a UAS operation in the Specific category. Therefore the SORA method [16] has been developed as an expert-based decision process to determine qualitative levels of risk posed by a UAS operation to third parties on the ground and to third parties in the air.

The SORA method is a decision process to assign requirements to the UAS operation that bring it under proper control with a sufficient level of confidence. The main steps of the SORA method are:

- Determination of the Ground Risk Class (GRC). Intrinsic GRC is determined using

- Table 5. Subsequently Table 6 show how mitigation measures reduce Intrinsic GRC to Final GRC. 
- Determination of the Air Risk Class (ARC). Initial ARC is determined using the process in Fig. 3. Strategic mitigations are identified to reduce the Initial ARC level to Residual ARC level. Subsequently Table 7 translates Residual ARC to Tactical Mitigation Performance Requirements (TMPR).

- $\quad$ Assignment of requirements. Table 8 translates Final GRC and Residual ARC into Specific Assurance and Integrity Level (SAIL); Table 9 translates SAIL into Operational Safety Objectives (OSO).

Neither [17] nor [16] provide an explanation how these main SORA steps make use of the quantitative equations in Fig. 1.

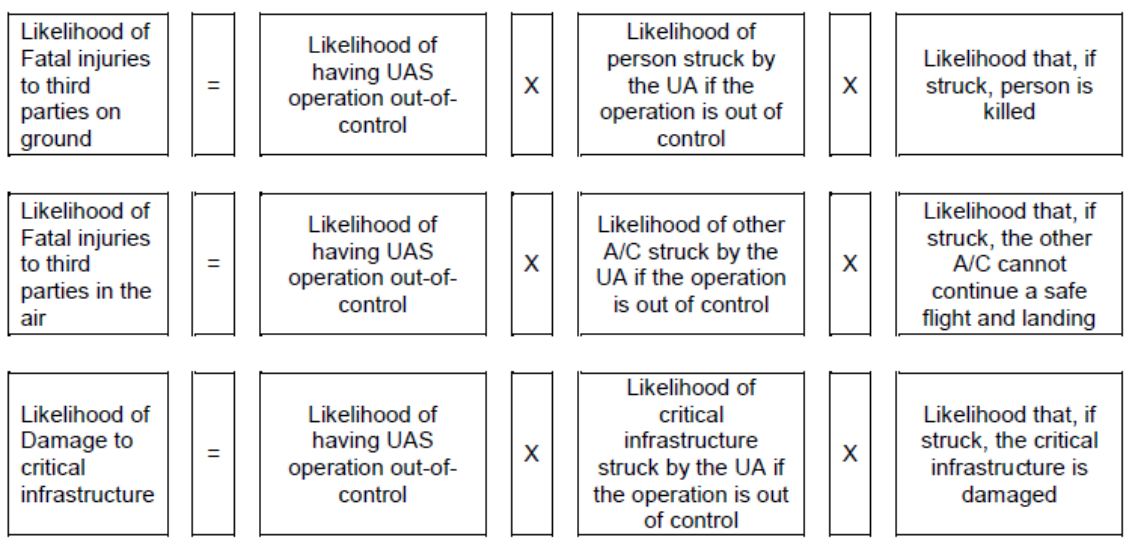

Fig. 1. Third party risk equations forming the basis of SORA (source: Fig. 5 in [17])

\section{AMC RPAS.1309 for Certified Category}

For Certified category UAS operations, an airworthiness certification process (AMC RPAS.1309 [13]) is adopted for UAS. Note that the use of this process is also applicable to other UAS categories (Open / Specific) if high airworthiness standard is needed (e.g. flight over crowds of people). Different types of UAS ranging from light UAS to conventional aircraft equivalent UAS are considered:

- $\quad$ LUAS (Light Unmanned Aeroplane System) [18];

- $\quad$ LURS (Light Unmanned Rotorcraft System) [19];

- RPAS-23 (Small unmanned airplane) [20];

- RPAS-25 (Large unmanned airplane) [21];

- RPAS-27 (Unmanned rotorcraft with MGTOW <=6000 pounds) [22];

- $\quad$ RPAS-29 (Unmanned rotorcraft with MGTOW > 6000 pounds) [23].

The risk requirements for these types of UAS are given in Table 10.

The definitions for the severity classes are shown in Table 11. Note that for the manned aircraft equivalent UAS (RPAS-23 Class IV, RPAS-25 and RPAS-29), existing mean of compliance for conventional aircraft ([21], [23] and [20]) are applied, however the severity definitions are different from that of UAS. The main difference lays in the hazardous and catastrophic classes. UAS severity definitions consider consequence of one or multiple fatalities as catastrophic, while conventional aircraft standards consider fatal injury to one occupant as hazardous and multiple fatalities as catastrophic.

\section{B. FAA UAS Safety Management Frameworks}

FAA regulatory framework [24] for UAS operations distinguishes the following three categories, the characteristics for each of these are shown in Table 2Error! Reference source not found.:

- Recreational UAS operation,

- Work/Business UAS operation,

- Advanced UAS operation.

For the recreational UAS category no safety risk assessment is required [25, 26]. For Work/Business UAS operation small unmanned aircraft rules apply [27] under certain constraints such as less than $55 \mathrm{lbs}$, VLOS only, not over persons (see Table 2Error! Reference source not found.). For the risk assessment of a work/business UAS operation, Advisory Circular 107-2 [28] applies, in which a qualitative overall safety risk assessment is encouraged though not obliged. All other UAS operations are considered to fall in the Advanced category; for such UAS operation a Safety Risk Management (SRM) is mandatory. Error! Reference source not found. Fig. 2 shows that the applicable SRM 
process depends on the UAS operating airspace. The two main risk management processes for Advanced UAS operations are:

- SRM [29] for UAS operation in uncontrolled airspace applying Order 8040.4B [30],

- SRM for UAS operation in controlled airspace applying ATO SMS Manual [31].

Order 8040.4B / UAS SRM Policy for Advanced Category

Order 8040.4B [30] is established for SRM for manned aviation. As a supplement to Order 8040.4B, UAS SRM policy [29] is established for conducting SRM for UAS requesting to operate in uncontrolled airspace (e.g. below 400ft in Class G airspace). UAS SRM Policy adopts the risk criteria for general aviation from Order 8040.4B. The risk matrix, likelihood and severity definitions are shown in Table 12 to Table 14.

Table 2. Characteristics of UAS Operations in FAA Safety Regulations [26, 27, 32-34]

\begin{tabular}{|c|c|c|c|}
\hline Category & Recreational & Work/Business & Advanced \\
\hline MTOW & $\mathrm{N} / \mathrm{A}$ & $<=25 \mathrm{~kg}$ & $\mathrm{~N} / \mathrm{A}$ \\
\hline Flying altitude & $\begin{array}{c}<=400 \mathrm{ft} \text { (Class G } \\
\text { airspace) / } \\
\text { Within UASFM altitude }\end{array}$ & $<=400 \mathrm{ft}$ & $\mathrm{N} / \mathrm{A}$ \\
\hline Range & VLOS & VLOS & VLOS / BVLOS \\
\hline Collaboration level & Single-UAS & Single-UAS & Single / Multi-UAS \\
\hline Autonomous level & Manually & Manually & Manually/Autonomous \\
\hline Flight ground speed & $\mathrm{N} / \mathrm{A}$ & $<=100 \mathrm{mph}$ & $\mathrm{N} / \mathrm{A}$ \\
\hline Flight time & $\mathrm{N} / \mathrm{A}$ & Daylight & Daylight / Night \\
\hline $\begin{array}{c}\text { Over uninvolved } \\
\text { person }\end{array}$ & Not allowed & Not allowed & Allowed \\
\hline $\begin{array}{l}\text { Risk assessment } \\
\text { requirement }\end{array}$ & Not required & Encouraged & Required \\
\hline $\begin{array}{l}\text { Authorisation/ } \\
\text { certification } \\
\text { requirement }\end{array}$ & $\begin{array}{c}\text { Aeronautical } \\
\text { Knowledge and Safety } \\
\text { Test, } \\
\text { Registered aircraft }\end{array}$ & $\begin{array}{l}\text { Remote pilot certificate, } \\
\text { Registered aircraft }\end{array}$ & $\begin{array}{l}\text { Remote pilot certificate, } \\
\text { Application for waiver / } \\
\text { exemption / certification }\end{array}$ \\
\hline Airspace & $\begin{array}{c}\text { Uncontrolled / } \\
\text { Controlled (FAA } \\
\text { authorized fixed sites) }\end{array}$ & $\begin{array}{c}\text { Uncontrolled / } \\
\text { Controlled (ATC permission) }\end{array}$ & Uncontrolled / Controlled \\
\hline Transportation & $\mathrm{N} / \mathrm{A}$ & No carriage of hazardous materials & $\mathrm{N} / \mathrm{A}$ \\
\hline
\end{tabular}

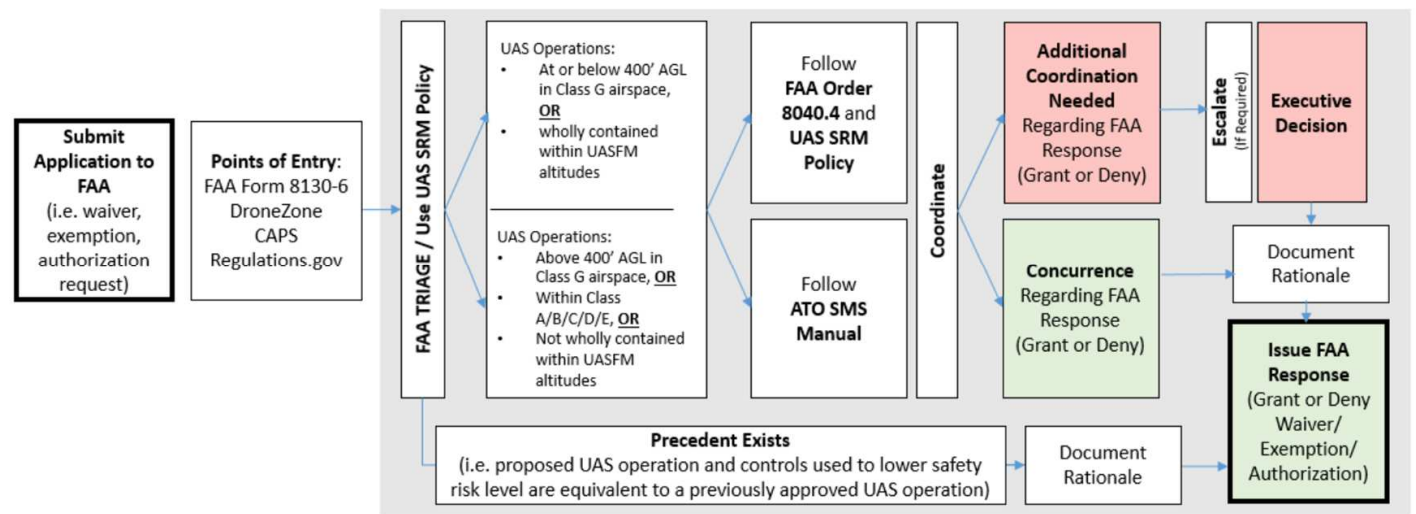

Fig. 2. SRM for an Advanced UAS Operation [29]

\section{ATO SMS Manual for Advance Category}

ATO SMS Manual [31] provides principles and guidelines for ATO (Air Traffic Organizations) to ensure safety operation, in which SRM is part of it. SRM in ATO SMS Manual is adopted for UAS operations in controlled airspace (e.g. above $400 \mathrm{ft}$ in Class $\mathrm{G}$ airspace or out of Class $\mathrm{G}$ airspace). The risk matrix and severity definitions are given in Table 15 and Table 16. The quantitative criteria for likelihood are given in Table 17 in terms of expected occurrence 
rate per operation/flight hour/operational hour. Which of these three occurrence rate units applies depends on the type of NAS change in ConOps [31]:

- $\quad$ per operation is applicable for a Terminal Radar Approach Control (TRACON) center, Air Route Traffic Control Center (ARTCC) with small, busy sectors, or an airport traffic control tower;

- per flight hour is applicable for the oceanic domain or for an ARTCC with a larger sector;

- per operational hour is applicable for a system acquisition or modification.

\section{Evaluation of UAS TPR Indicators}

This section first evaluates which of the eight third-party fatality terms defined in section III are covered by each of the EASA and FAA regulations. The details of this evaluation is shown in Table 3. Subsequently Eq. (10)-(13) are used to translate this in terms of the UAS TPR indicators; these results are shown in Table 4. Subsequently the findings in Tables 3 and 4 are discussed.

Table 3. Third-party fatality terms that are addressed by EASA and FAA regulations

\begin{tabular}{|c|c|c|c|c|c|c|}
\hline \multirow{3}{*}{$\begin{array}{c}\text { Third-party } \\
\text { fatality terms of } \\
i \text {-th UAS flight }\end{array}$} & \multicolumn{6}{|c|}{ Regulations \& Operation category } \\
\hline & \multirow{2}{*}{$\begin{array}{c}\text { EASA/JARUS } \\
\text { SORA } \\
\text { Open } \\
\text { /Specific } \\
\text { /Certified }\end{array}$} & \multicolumn{2}{|c|}{$\begin{array}{c}\text { EASA/JARUS } \\
\text { AMC RPAS.1309 }\end{array}$} & \multirow{2}{*}{$\begin{array}{c}\text { FAA } \\
\text { Advisory } \\
\text { Circular 107-2 } \\
\text { Work } \\
\text { /business }\end{array}$} & \multirow{2}{*}{$\begin{array}{c}\text { FAA } \\
\text { UAS SRM policy } \\
\text { /order } 8040.4 B \\
\begin{array}{c}\text { Advanced } \\
\text { (in uncontrolled } \\
\text { airspace) }\end{array}\end{array}$} & \multirow{2}{*}{$\begin{array}{c}\text { FAA } \\
\begin{array}{c}\text { ATO SMS } \\
\text { Manual }\end{array} \\
\begin{array}{c}\text { Advanced } \\
\text { (in controlled } \\
\text { airspace) }\end{array}\end{array}$} \\
\hline & & $\begin{array}{l}\text { Certified } \\
\text { (for ground } \\
\text { risk) }\end{array}$ & $\begin{array}{l}\text { Certified } \\
\text { (for air } \\
\text { risk) }\end{array}$ & & & \\
\hline 1. $E\left\{n_{F_{\text {UASground }}}^{i}\right\}$ & Yes*) & Yes & - & Yes*) & Yes & Yes \\
\hline 2. $E\left\{n_{F_{\text {UASair }}}^{i}\right\}$ & - & - & - & - & - & Yes \\
\hline 3. $E\left\{n_{F_{\text {CATonboard }}}^{i}\right\}$ & Yes*) & - & Yes & - & - & Yes \\
\hline 4. $E\left\{n_{F_{\text {CATground }}}^{i}\right\}$ & - & - & - & - & - & Yes \\
\hline 5. $E\left\{n_{F_{\text {GAnboard }}}^{i}\right\}$ & Yes*) & - & Yes & - & - & Yes \\
\hline 6. $E\left\{n_{F_{\text {GAground }}}^{i}\right\}$ & - & - & & - & - & Yes \\
\hline 7. $E\left\{n_{F_{\text {UAMonboard }}}^{i}\right\}$ & Yes*) & - & Yes & - & - & Yes \\
\hline 8. $E\left\{n_{F_{\text {UAMground }}}^{i}\right\}$ & - & - & - & - & - & Yes \\
\hline
\end{tabular}

*) No quantification

Table 4. Applicable UAS TPR Indicators

\begin{tabular}{|c|c|c|}
\hline Regulation/Policy & Operation Category & Applicable TPR Indicator \\
\hline $\begin{array}{l}\text { EASA/JARUS } \\
\text { SORA }\end{array}$ & Open/Specific/Certified & - \\
\hline \multirow{2}{*}{$\begin{array}{c}\text { EASA/JARUS } \\
\text { AMC RPAS.1309 }\end{array}$} & $\begin{array}{c}\text { Certified } \\
\text { (for ground risk) }\end{array}$ & $\begin{array}{c}\left.R_{\text {Cground }}^{i} *\right) \text { per hazard and } \\
\text { per flight hour }\end{array}$ \\
\hline & $\begin{array}{c}\text { Certified } \\
\text { (for mid-air collision risk) }\end{array}$ & $\begin{array}{l}R_{C}^{i} \text { on-board per hazard } \\
\text { and per flight hour }\end{array}$ \\
\hline $\begin{array}{c}\text { FAA } \\
\text { Advisory Circular 107-2 }\end{array}$ & Work/business & - \\
\hline $\begin{array}{c}\text { FAA } \\
\text { Order } 8040.4 B\end{array}$ & $\begin{array}{c}\text { Advanced } \\
\text { (in uncontrolled airspace) }\end{array}$ & $\begin{array}{l}\left.R_{\text {Cground }}^{i} *\right) \text { per hazard and } \\
\text { per year UAS operation }\end{array}$ \\
\hline $\begin{array}{c}\text { FAA } \\
\text { ATO SMS Manual }\end{array}$ & $\begin{array}{c}\text { Advanced } \\
\text { (in controlled airspace) }\end{array}$ & $\begin{array}{c}R_{C}^{i} \text { per hazard and per } \\
\text { flight hour }\end{array}$ \\
\hline
\end{tabular}

*) excluding ground fatalities due to a preceding mid-air collision

\section{EASA/JARUS SORA}


From the explanation provided in section IV.A, it is clear that the SORA method aims to cover both third party fatalities on the ground and on-board of manned aircraft. However none of these assessments is aimed to be quantitative. Moreover the SORA method does not aim to address any of the even terms in Table 3, i.e. follow-up consequences of a preceding mid-air collision of a UAS with a manned aircraft or with another UAS. The qualitative nature of SORA means that there is no contribution in Table 4.

\section{EASA/JARUS AMC RPAS.1309}

AMC RPAS.1309 is adopted for EASA/JARUS Certified category. Risk is evaluated per hazard and per UAS flight hour. In [35], catastrophic failure condition refers to "one or more fatalities that can occur either in the air (midair collision) or on the ground". Subsequently risk posed to third parties on the ground and in the air risk are addressed separately.

- For third parties on the ground, $[2,35]$ assumes that risk is a function of accident rate, population density, impact dynamics, and area of impact. It is further explained that accident rate is here meant to include UAS failures though not mid-air collision. For Table 3 this means that the first term $E\left\{n_{F_{U A A g r o u n d}}^{i}\right\}$ is covered, but not the second term $E\left\{n_{F_{U A S a i r}}^{i}\right\}$. For Table 4 this means that $R_{\text {Cground }}^{i}$ is partly covered.

- For third parties in the air, a mid-air collision with a manned aircraft is considered as having catastrophic consequences [35]. For Table 3 this means that the on-board third-party fatality terms $\left(E\left\{n_{F_{C A T o n b o a r d}}^{i}\right\}\right.$, $E\left\{n_{F_{\text {GAnboard }}}^{i}\right\}$ and $\left.E\left\{n_{F_{U A M o n b a r d}}^{i}\right\}\right)$ are covered. However the ground fatality terms that represent ground fatalities after a mid-air collision are not covered. Mid-air collisions between UAS is not covered; hence the second term $E\left\{n_{F_{U A S a i r}}^{i}\right\}$ is not covered. For Table 4 the above means that the on-board parts of $R_{C}^{i}$ are covered.

\section{FAA Advisory Circular 107-2}

Advisory Circular 107-2 [28] provides an example of risk assessment for UAS operation, in which third-party fatality for ground collision of an UAS is considered. For Table 3 this means that the first term $E\left\{n_{F_{U A S \text { ground }}}^{i}\right\}$ is covered. However there is no quantification as the evaluation of likelihood is qualitative. For Table 4 this means there is no contribution.

\section{FAA Order 8040.4B / UAS SRM Policy}

Order 8040.4B [30] and UAS SRM Policy [29] is adopted for FAA Advanced category with UAS operation in uncontrolled airspace. Risk is evaluated per hazard and per year of the UAS operation. Third party risk for persons on the ground is addressed; hence the first term $E\left\{n_{F_{U A S} \text { round }}^{i}\right\}$ is covered. Because in uncontrolled airspace there is no collision of a UAS with a manned aircraft the terms 3 through 8 are not covered. Possible collisions between two UAS are neither considered; hence the second term $E\left\{n_{F_{U A S a i r}}^{i}\right\}$ in Table 3 is not covered. For Table 4 this means that $R_{\text {Cground }}^{i}$ is partly covered.

\section{FAA ATO SMS Manual}

FAA ATO SMS Manual is adopted for FAA Advanced category with UAS operation in controlled airspace. Risk is evaluated per hazard and per UAS flight hour. In Table 16, the phrase "fatality or fatal injury to persons other than the unmanned aircraft system crew" refers to all types of third-party fatalities. This means that both third parties on board and on the ground due to an accident involving a UAS are covered; hence all eight terms in Table 3 are covered. For Table 4 this means that $R_{C}^{i}$ is fully covered.

\section{Discussion of results in Tables 3-4}

The results in Tables 3-4 show that for medium risk UAS operations the safety management frameworks of EASA/JARUS and FAA do not address TPR indicators. Tables 3-4 also show that the situation is better for high risk UAS operations. For UAS operations in controlled airspace the FAA safety risk management framework covers all eight third party terms. For UAS operations in uncontrolled airspace the FAA safety risk management framework only considers the first term, i.e. ground fatalities due to a UAS crash to the ground, if this UAS has not been subject of a 
preceding mid-air collision with another UAS. The Certified risk management framework of EASA/JARUS even excludes all ground fatality consequences from a preceding mid-air collision, i.e. both between two UAS and between a UAS and a manned aircraft. The results also show that none of the risk management frameworks evaluated address the accumulation of contributions from multiple UAS flights to the TPR indicators $R_{C}, R_{C g r o u n d}$ and $R_{I}(s)$.

\section{Conclusion}

This paper has studied TPR indicators for UAS operations and their use in EASA/JARUS and FAA safety regulations. In commercial aviation the TPR indicators are Individual risk, Collective risk and Societal risk; each of these three addresses fatality risk posed to persons on the ground only. In addition to posing risk to persons on the ground, UAS operations may also pose third party risks to crew and passengers on board manned aircraft. In section III this is captured through the definition of three TPR indicators for UAS operations: i) Collective risk $R_{C}$ for expected number of fatalities due to UAS operations; ii) Collective ground risk $R_{\text {Cground }}$ for expected number of fatalities on the ground due to UAS operations; and iii) Individual risk $R_{I}(s)$ for the probability that an unprotected person at ground location $s$ will be killed due to UAS operations. The latter two (ii and iii) consider ground fatalities only, which is similar to Collective risk and Individual risk of commercial aviation. The newly proposed TPR indicator (i) also considers fatalities on-board manned aircraft due to a collision with a UAS. To make the definitions of $R_{C}$, $R_{\text {Cground }}$ and $R_{I}(s)$ explicit, the contributions $R_{C}^{i}, R_{C g r o u n d}^{i}$ and $R_{I}^{i}(s)$ by the $i$-th UAS flight have been characterized in detail.

In Section IV the UAS safety regulations from EASA/JARUS and FAA for different types of UAS operations are identified and subsequently analysed regarding the applicable risk assessment methods. Both EASA/JARUS and FAA distinguish three categories of UAS operations: i) Low risk category (Open in EASA/JARUS, Recreation in FAA); ii) Medium risk category (Specific in EASA/JARUS, Work/Business in FAA); and iii) High risk category (Certified in EASA/JARUS, Advanced in FAA). For the low risk category safety risk assessment is not required. For the medium risk category, both EASA/JARUS and FAA propose qualitative assessment methods (SORA and Advisory Circular 107-2 respectively). For high risk category, both EASA/JARUS and FAA prescribe quantitative safety risk assessment methods. For each of these safety risk assessment methods the basic steps have been reviewed.

In section $V$ the safety assessment frameworks of EASA/JARUS and FAA have been evaluated against the TPR indicators for UAS operations which have been developed in section III. This evaluation shows that the EASA/JARUS and FAA methods for the medium risk category UAS operations (SORA and Advisory Circular 107-2) do not address any of the TPR indicators. For the high risk category of UAS operations the safety frameworks of EASA/JARUS and FAA address relevant contributions to $R_{C}^{i}$ and $R_{C \text { ground }}^{i}$. For controlled airspace the FAA methods cover all possible contributions. For uncontrolled airspace the FAA methods cover ground fatalities due to a UAS crash to the ground that was not been preceded by a mid-air collision. The EASA/JARUS risk assessment methods addresses either onboard fatalities due to a mid-air collision or ground fatalities due to a UAS crash to the ground that was not preceded by a mid-air collision. None of the safety methods from EASA/JARUS and FAA cover the accumulation to TPR indicators $R_{C}$ and $R_{C g r o u n d}$ and $R_{I}(s)$ by many UAS flights per annum over a given area.

The main conclusions that can be drawn from this study are twofold. Firstly, for medium risk UAS operations none of the current regulations require assessment of any contribution to relevant TPR indicators. Secondly, the identified focus of EASA/JARUS and FAA on methods that assess the TPR contributions per individual UAS operation, means that these methods fall short in capturing the accumulation of contributions by many UAS flights per annum to TPR indicators $R_{C}$ and $R_{\text {Cground }}$ and $R_{I}(s)$ for rural or urban areas.

To grasp the criticality of these main conclusions, imagine a commercial UAS operation involving a very large number of UAS flights per annum over a rural or urban area that falls outside controlled airspace. For each individual UAS flight at most a quantitative assessment of (a part of) $R_{\text {Cground }}^{i}$ is required. However, what is not required is to assess if the accumulation of the $R_{C g r o u n d}^{i}$ contributions to $R_{C g r o u n d}$ and $R_{I}(s)$ remain acceptably safe if the annual number of UAS flights in an urban area keeps on growing. This example shows that in order to safely manage future increase of UAS flights over rural and urban areas, there is a need for the development of a quantitative safety management framework which addresses the accumulation of individual UAS flight contributions to Collective ground risk $R_{\text {Cground }}$ and to Individual risk $R_{I}(s)$. 
Appendix

Table 5. SORA's Intrinsic GRC Determination [16]

\begin{tabular}{|l|c|c|c|c|}
\hline \multicolumn{5}{|c|}{ Intrinsic UAS Ground Risk Class } \\
\hline Max UAS characteristics dimension & $\begin{array}{c}1 \mathrm{~m} / \text { approx. } \\
3 \mathrm{ft}\end{array}$ & $\begin{array}{c}3 \mathrm{~m} / \text { approx. } \\
10 \mathrm{ft}\end{array}$ & $\begin{array}{c}8 \mathrm{~m} / \text { approx. } \\
25 \mathrm{ft}\end{array}$ & $\begin{array}{c}>8 \mathrm{~m} / \text { approx. } \\
25 \mathrm{ft}\end{array}$ \\
\hline Typical kinetic energy expected & $\begin{array}{c}<700 \mathrm{~J} \\
\text { (approx. } 529 \\
\text { Ft Lb) }\end{array}$ & $\begin{array}{c}<34 \mathrm{KJ} \\
\text { (approx. } \\
25000 \mathrm{Ft} \text { Lb) }\end{array}$ & $\begin{array}{c}<1084 \mathrm{KJ} \\
\text { (approx. } \\
800000 \mathrm{Ft} L \text { Lb) }\end{array}$ & $\begin{array}{c}>1084 \mathrm{KJ} \\
\text { (approx. } \\
800000 \mathrm{Ft} \mathrm{Lb} \text { ) }\end{array}$ \\
\hline \multicolumn{1}{|c|}{ Operational scenarios } & 1 & 2 & 3 & 4 \\
\hline VLOS/BVLOS over controlled ground area & 2 & 2 & 4 & 5 \\
\hline VLOS in sparsely populated environment & 2 & 3 & 5 & 6 \\
\hline BVLOS in sparsely populated environment & 3 & 4 & 6 & 8 \\
\hline VLOS in populated environment & 4 & 5 & 8 & 10 \\
\hline BVLOS in populated environment & 5 & 6 & & \\
\hline VLOS over gathering of people & 7 & & & \\
\hline BVLOS over gathering of people & 8 & & & \\
\hline
\end{tabular}

Table 6. SORA's Mitigations for Final GRC determination [16]

\begin{tabular}{|c|l|c|c|c|}
\hline $\begin{array}{l}\text { Mitigation } \\
\text { Sequence }\end{array}$ & Mitigations for ground risk & \multicolumn{2}{|c|}{ Robustness } & High \\
\hline 1 & $\begin{array}{l}\text { M1 - Strategic mitigations for ground } \\
\text { risk }\end{array}$ & $\begin{array}{l}\text { 0: None } \\
-1: \text { Low }\end{array}$ & -2 & -4 \\
\hline 2 & $\begin{array}{l}\text { M2 - Effects of ground impact are } \\
\text { reduced }\end{array}$ & 0 & -1 & -2 \\
\hline 3 & $\begin{array}{l}\text { M3 - An Emergency Response Plan (ERP) } \\
\text { is in place, operator validated and } \\
\text { effective }\end{array}$ & 1 & 0 & -1 \\
\hline
\end{tabular}

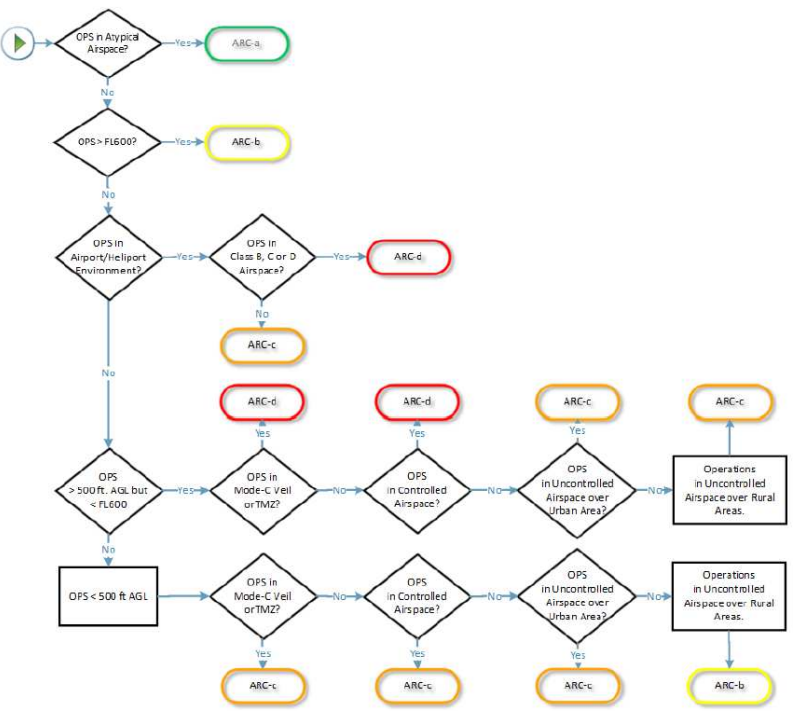

Fig. 3. SORA ARC assignment process [16]

Table 7. SORA's TMPR and TMPR level of Robustness Assignment [16]

\begin{tabular}{|c|c|c|}
\hline Residual ARC & $\begin{array}{c}\text { Tactical Mitigation } \\
\text { Performance Requirements } \\
\text { (TMPR) }\end{array}$ & $\begin{array}{c}\text { TMPR Level of } \\
\text { Robustness }\end{array}$ \\
\hline ARC-d & High & High \\
\hline ARC-c & Medium & Medium \\
\hline ARC-b & Low & Low \\
\hline ARC-a & No requirement & No requirement \\
\hline
\end{tabular}


Table 8. SORA SAIL determination [16]

\begin{tabular}{|l|c|c|c|c|}
\hline \multicolumn{5}{|c|}{ SAIL Determination } \\
\hline & \multicolumn{4}{|c|}{ Residual ARC } \\
\hline $\begin{array}{l}\text { Final } \\
\text { GRC }\end{array}$ & a & b & c & d \\
\hline$\leq 2$ & I & II & IV & VI \\
\hline 3 & II & II & IV & VI \\
\hline 4 & III & III & IV & VI \\
\hline 5 & IV & IV & IV & VI \\
\hline 6 & V & V & V & VI \\
\hline 7 & VI & VI & VI & VI \\
\hline$>7$ & \multicolumn{5}{|c|}{ Category C operation } \\
\hline
\end{tabular}

Table 9. SORA's Recommended OSO [16]

\begin{tabular}{|c|c|c|c|c|c|c|c|}
\hline \multirow{2}{*}{$\begin{array}{l}\text { OSO } \\
\text { Number (in } \\
\text { line with } \\
\text { Annex E) }\end{array}$} & & \multicolumn{6}{|c|}{ SAIL } \\
\hline & & 1 & II & III & IV & v & VI \\
\hline & Technical issue with the UAS & & & & & & \\
\hline OSO\#01 & $\begin{array}{l}\text { Ensure the operator is competent } \\
\text { and/or proven }\end{array}$ & 0 & $\mathrm{~L}$ & $M$ & $\mathrm{H}$ & $\mathrm{H}$ & $\mathrm{H}$ \\
\hline OSO\#02 & $\begin{array}{l}\text { UAS manufactured by competent } \\
\text { and/or proven entity }\end{array}$ & 0 & 0 & $L$ & $M$ & $\mathrm{H}$ & $\mathrm{H}$ \\
\hline
\end{tabular}

\section{B. JARUS Safety Risk Criteria}

Table 10. AMC RPAS.1309 Safety Risk Requirement [13]

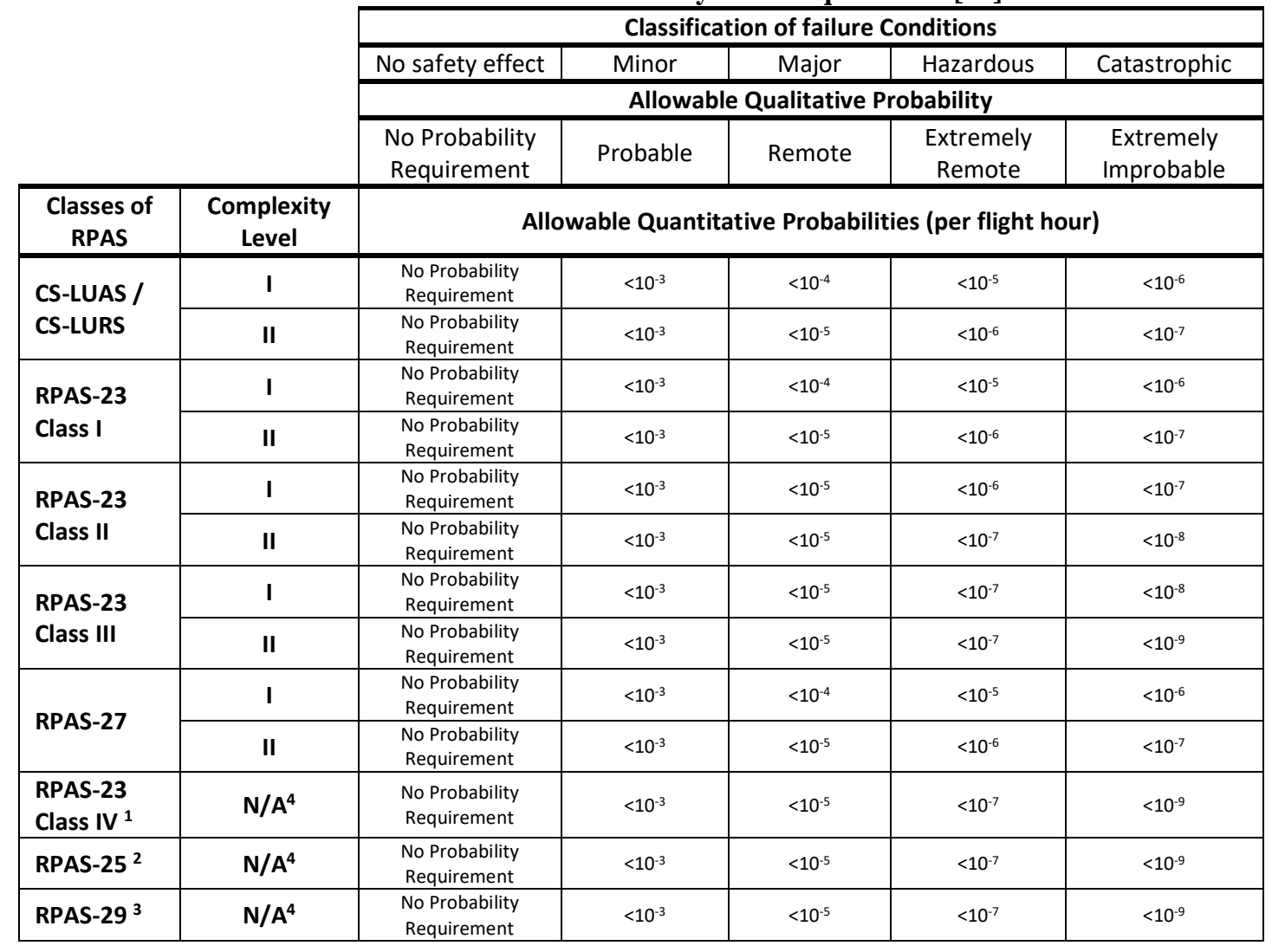


1. The probability requirement is from AC 23.1307-1E [20].

2. The probability requirement is from AMC 25.1309 [21].

3. The probability requirement is from AC 29-2C [23]

4. Large RPAS systems are deemed to be complex (i.e. Equivalent to CL II)

Table 11. AMC RPAS.1309 Safety Risk Severity Definitions [13]

\begin{tabular}{|c|c|c|c|c|}
\hline No safety effect & Minor & Major & Hazardous & Catastrophic \\
\hline $\begin{array}{l}\text { Failure conditions that } \\
\text { would have no effect } \\
\text { on safety. For example, } \\
\text { failure conditions that } \\
\text { would not affect the } \\
\text { operational capability } \\
\text { of the RPAS or increase } \\
\text { the remote crew } \\
\text { workload. }\end{array}$ & $\begin{array}{l}\text { Failure conditions that } \\
\text { would not significantly } \\
\text { reduce RPAS safety and } \\
\text { that involve remote crew } \\
\text { actions that are within } \\
\text { their capabilities. Minor } \\
\text { failure conditions may } \\
\text { include a slight reduction } \\
\text { in safety margins or } \\
\text { functional capabilities, a } \\
\text { slight increase in remote } \\
\text { crew workload, such as } \\
\text { flight plan changes. }\end{array}$ & $\begin{array}{l}\text { Failure conditions that would } \\
\text { reduce the capability of the RPAS } \\
\text { or the ability of the remote crew } \\
\text { to cope with adverse operating } \\
\text { conditions to the extent that } \\
\text { there would be a significant } \\
\text { reduction in safety margins, } \\
\text { functional capabilities or } \\
\text { separation assurance. In } \\
\text { addition, the failure condition } \\
\text { has a significant increase in } \\
\text { remote crew workload or impairs } \\
\text { remote crew efficiency. }\end{array}$ & $\begin{array}{l}\text { Failure conditions that would reduce the } \\
\text { capability of the RPAS or the ability of } \\
\text { the remote crew to cope with adverse } \\
\text { operating conditions to the extent that } \\
\text { there would be the following: } \\
\text { (i) Loss of the RPA where it can be } \\
\text { reasonably expected that a fatality will } \\
\text { not occur, } \\
\text { (ii) A large reduction in safety margins or } \\
\text { functional capabilities, } \\
\text { (iii) High workload such that the remote } \\
\text { crew cannot be relied upon to perform } \\
\text { their tasks accurately or completely. }\end{array}$ & $\begin{array}{l}\text { Failure conditions } \\
\text { that could result in } \\
\text { one or more } \\
\text { fatalities. }\end{array}$ \\
\hline
\end{tabular}

\section{FAA Order 8040.4B / UAS SRM Policy Safety Risk Criteria}

Table 12. Risk Matrix of UAS SRM Policy and Order 8040.4B [30]

\begin{tabular}{|c|c|c|c|c|c|}
\hline Severity & $\underset{5}{\operatorname{Minimal}}$ & $\underset{4}{M i n o r}$ & $\underset{3}{\text { Major }}$ & $\begin{array}{c}\text { Hazardous } \\
\mathbf{2}\end{array}$ & $\underset{1}{\text { Catastrophic }}$ \\
\hline Frequent & [Green] & [Yellow] & [Red] & [Red] & [Red] \\
\hline $\begin{array}{l}\text { Probable } \\
B\end{array}$ & [Green] & [Yellow] & [Yellow] & [Red] & [Red] \\
\hline Remote & [Green] & [Green] & [Yellow] & [Yellow] & [Red] \\
\hline $\begin{array}{c}\text { Extremely } \\
\text { Remote } \\
\text { D }\end{array}$ & [Green] & [Green] & [Green] & [Yellow] & \\
\hline $\begin{array}{c}\text { Extremely } \\
\text { Improbable } \\
\text { E }\end{array}$ & [Green] & [Green] & [Green] & [Green] & [Yellow] \\
\hline & & \multicolumn{2}{|c|}{ High Risk [Red] } & \multirow{3}{*}{\multicolumn{2}{|c|}{$\begin{array}{l}\text { * High Risk with Single } \\
\text { Point and/or Common } \\
\text { Cause Failures }\end{array}$}} \\
\hline & & \multicolumn{2}{|c|}{ Medium Risk [Yellow] } & & \\
\hline & & Low Ris & [Green] & & \\
\hline
\end{tabular}

Table 13. Severity Definitions of UAS SRM Policy and Order 8040.4B [30]

\begin{tabular}{|c|c|c|c|c|}
\hline $\begin{array}{c}\text { Minimal } \\
5\end{array}$ & $\begin{array}{c}\text { Minor } \\
4\end{array}$ & $\begin{array}{c}\text { Major } \\
\mathbf{3}\end{array}$ & $\begin{array}{c}\text { Hazardous } \\
2\end{array}$ & $\begin{array}{c}\text { Catastrophic } \\
1\end{array}$ \\
\hline $\begin{array}{l}\text { Negligible safety } \\
\text { effect }\end{array}$ & $\begin{array}{l}\text { Physical discomfort to } \\
\text { persons } \\
\text { Slight damage to } \\
\text { aircraft/vehicle }\end{array}$ & $\begin{array}{l}\text { Physical distress or } \\
\text { injuries to persons } \\
\text { Substantial damage to } \\
\text { aircraft/vehicle }\end{array}$ & $\begin{array}{l}\text { Multiple serious injuries; fatal } \\
\text { injury to a relatively small } \\
\text { number of persons (one or two); } \\
\text { or a hull loss without fatalities }\end{array}$ & $\begin{array}{l}\text { Multiple fatalities (or } \\
\text { fatality to all on board) } \\
\text { usually with the loss of } \\
\text { aircraft/ vehicle }\end{array}$ \\
\hline
\end{tabular}

Table 14. Likelihood Definitions of UAS SRM Policy and Order 8040.4B [30]

\begin{tabular}{|c|l|l|}
\hline \multicolumn{1}{|c|}{ Qualitative } & \multicolumn{1}{c|}{ Quantitative } \\
\hline $\begin{array}{c}\text { Frequent } \\
\text { A }\end{array}$ & Expected to occur routinely & $\begin{array}{l}\text { Expected to occur more than 100 times per year (or } \\
\text { more than approximately 10 times a month) }\end{array}$ \\
\hline $\begin{array}{c}\text { Probable } \\
\text { B }\end{array}$ & Expected to occur often & $\begin{array}{l}\text { Expected to occur between 10 and 100 times per year } \\
\text { (or approximately 1-10 times a month) }\end{array}$ \\
\hline $\begin{array}{c}\text { Remote } \\
\text { C }\end{array}$ & Expected to occur infrequently & Expected to occur one time every 1 month to 1 year \\
\hline $\begin{array}{c}\text { Extremely } \\
\text { Remote } \\
\text { D }\end{array}$ & Expected to occur rarely & Expected to occur one time every 1 to 10 years \\
\hline $\begin{array}{c}\text { Extremely } \\
\text { Improbable } \\
\text { E }\end{array}$ & $\begin{array}{l}\text { Unlikely to occur, but not } \\
\text { impossible }\end{array}$ & Expected to occur less than one time every 10 years \\
\hline
\end{tabular}




\section{ATO SMS Safety Risk Criteria}

Table 15. ATO SMS Manual Risk Matrix [31]

\begin{tabular}{|c|c|c|c|c|c|}
\hline Likelihood & $\begin{array}{c}\text { Minimal } \\
5\end{array}$ & $\begin{array}{c}\text { Minor } \\
4\end{array}$ & $\begin{array}{c}\text { Major } \\
3\end{array}$ & $\begin{array}{c}\text { Hazardous } \\
2\end{array}$ & $\begin{array}{c}\text { Catastrophic } \\
1\end{array}$ \\
\hline $\begin{array}{l}\text { Frequent } \\
\text { A }\end{array}$ & Low & Medium & High & High & High \\
\hline $\begin{array}{c}\text { Probable } \\
\text { B }\end{array}$ & Low & Medium & High & High & High \\
\hline $\begin{array}{c}\text { Remote } \\
\text { C }\end{array}$ & Low & Medium & Medium & High & High \\
\hline $\begin{array}{c}\text { Extremely Remote } \\
\text { D }\end{array}$ & Low & Low & Medium & Medium & High \\
\hline $\begin{array}{l}\text { Extremely Improbable } \\
\text { E }\end{array}$ & Low & Low & Low & Medium & Medi \\
\hline
\end{tabular}

Table 16. ATO SMS Manual Severity Definitions [31]

\begin{tabular}{|c|c|c|c|c|}
\hline Minimal 5 & Minor 4 & Major 3 & Hazardous 2 & Catastrophic 1 \\
\hline $\begin{array}{l}\text { Discomfort to } \\
\text { those on the } \\
\text { ground. } \\
\text { Loss of } \\
\text { separation } \\
\text { leading to a } \\
\text { measure of } \\
\text { compliance } \\
\text { greater than or } \\
\text { equal to } 66 \\
\text { percent. }\end{array}$ & $\begin{array}{l}\text { Low Risk } \\
\text { Analysis Event } \\
\text { severity, two or } \\
\text { fewer indicators } \\
\text { fail*. } \\
\text { Non-serious } \\
\text { injury to three } \\
\text { or fewer people } \\
\text { on the ground }\end{array}$ & $\begin{array}{l}\text { Medium Risk Analysis Event } \\
\text { severity, three indicators fail. } \\
\text { Non-serious injury to more } \\
\text { than three people on the } \\
\text { ground. } \\
\text { A reduced ability of the crew } \\
\text { to cope with adverse operating } \\
\text { conditions to the extent that } \\
\text { there would be a significant } \\
\text { reduction in safety margins. } \\
\text { Manned aircraft making an } \\
\text { evasive maneuver, but } \\
\text { proximity from unmanned } \\
\text { aircraft remains greater than } \\
500 \text { feet. }\end{array}$ & $\begin{array}{l}\text { High Risk Analysis } \\
\text { Event severity, four } \\
\text { indicators fail. } \\
\text { Incapacitation to } \\
\text { unmanned aircraft } \\
\text { system crew. } \\
\text { Proximity of less } \\
\text { than } 500 \text { feet to a } \\
\text { manned aircraft. } \\
\text { Serious injury to } \\
\text { persons other than } \\
\text { the unmanned } \\
\text { aircraft System } \\
\text { crew. }\end{array}$ & $\begin{array}{l}\text { A collision with a } \\
\text { manned aircraft. } \\
\text { Fatality or fatal } \\
\text { injury to persons } \\
\text { other than the } \\
\text { unmanned aircraft } \\
\text { system crew. }\end{array}$ \\
\hline
\end{tabular}

*Risk Analysis Event severity indicators are as follows:

a. Proximity. Failure transition point of 50 percent of required separation or less.

b. Rate of Closure. Failure transition point greater than 205 knots or 2,000 feet per minute(consider both aspects and utilize the higher of the two if only one lies above the transition point).

c. ATC Mitigation. ATC able to implement separation actions in a timely manner.

d. Pilot Mitigation. Pilot executed ATC mitigation in a timely manner.

Table 17. ATO SMS Manual Likelihood Definition [31]

\begin{tabular}{|c|c|}
\hline Likelihood & $\begin{array}{c}\text { Operations: Expected Occurrence Rate } \\
\text { (per operation / flight hour / operational hour) }\end{array}$ \\
\hline $\begin{array}{c}\text { Frequent } \\
\text { A }\end{array}$ & (Probability) $\geq 1$ per 1000 \\
\hline $\begin{array}{c}\text { Probable } \\
\text { B }\end{array}$ & 1 per $1000>$ (Probability) $\geq 1$ per 100,000 \\
\hline $\begin{array}{c}\text { Remote } \\
\text { C }\end{array}$ & 1 per $100,000>$ (Probability) $\geq 1$ per $10,000,000$ \\
\hline $\begin{array}{c}\text { Extremely Remote } \\
\text { D }\end{array}$ & 1 per $10,000,000>$ (Probability) $\geq 1$ per $1,000,000,000$ \\
\hline $\begin{array}{c}\text { Extremely Improbable } \\
\text { E }\end{array}$ & 1 per $1,000,000,000>$ (Probability) $\geq 1$ per $10^{14}$ \\
\hline
\end{tabular}




\section{References}

[1] EUROCONTROL, "UAS ATM Integration Operational Concept," European Organisation for the Safety of Air Navigation, Edition: 1.0, 27th, Nov, 2018.

[2] Lin, X., Fulton, N. L., and Horn, M. E. T. 'Quantification of High Level Safety Criteria for Civil Unmanned Aircraft Systems,' IEEE Aerospace Conference, Big Sky, MT, 19th, June, 2014. doi: 10.1109/AERO.2014.6836463

[3] Stöcker, E. C., Bennett, R., Nex, F., Gerke, M., and Zevenbergen, J. A. "Review of the current state of UAV regulations," Remote sensing Vol. 9, No. 5, 2017, p. 459.

doi: $10.3390 / \mathrm{rs} 9050459$

[4] EUROCONTROL, "Feasibility study on the integration of third party risk near airports into IMPACT," European Organisation for the Safety of Air Navigation, Deliverable D2, 15th, June, 2015.

[5] Jonkman, S., Van Gelder, P., and Vrijling, J. "An overview of quantitative risk measures for loss of life and economic damage," Journal of hazardous materials Vol. 99, No. 1, 2003, pp. 1-30. doi: 10.1016/S0304-3894(02)00283-2

[6] Bohnenblust, H. "Risk-based decision making in the transportation sector," Quantified societal risk and policy making. Springer, 1998, pp. 132-153.

[7] Bottelberghs, P. H. "Risk analysis and safety policy developments in the Netherlands," Journal of Hazardous Materials Vol. 71, No. 2000, 2000, pp. 59-84.

doi: 10.1016/S0304-3894(99)00072-2

[8] Smets, H. "Frequency distribution of the consequences of accidents involving hazardous substances in OECD countries," Etudes et Dossiers, 1996.

[9] Laheij, G. M., Post, J. G., and Ale, B. J. "Standard methods for land-use planning to determine the effects on societal risk," Journal of Hazardous Materials Vol. 71, 2000, pp. 269-282.

doi: 10.1016/s0304-3894(99)00083-7

[10] Evans, A. W., and Verlander, N. Q. "What is wrong with criterion FN - lines for judging the tolerability of risk?," Risk analysis Vol. 17, No. 2, 1997, pp. 157-168.

doi: 10.1111/j.1539-6924.1997.tb00855.x

[11] Clothier, R. A., Williams, B. P., and Hayhurst, K. J. "Modelling the risks remotely piloted aircraft pose to people on the ground," Safety science Vol. 101, 2018, pp. 33-47. doi: 10.1016/j.ssci.2017.08.008

[12] EASA, "Concept of Operations for Drones: A risk based approach to regulation of unmanned aircraft," European Union Aviation Safety Agency, 1st, May, 2015.

[13] JARUS, "AMC RPAS.1309: Safety Assessment of Remotely Piloted Aircraft Systems," Joint Authorities for Rulemaking of Unmanned Systems, Issue: 2, Nov, 2015.

[14] EU, "Commision Delegated Reulation," European Union, 12th, Mar, 2019.

[15] EU, "Commision Implementing Regulation," European Union, 24th, May, 2019.

[16] JARUS, "JARUS guidances on Specific Operations Risk Assessment (SORA)," Joint Authorities for Rulemaking of Unmanned Systems, Edition: 2.0, 30th, Jan, 2019.

[17] JARUS, "JARUS guidelines on Specific Operations Risk Assessment (SORA)," Joint Authorities for Rulemaking of Unmanned Systems, Edition: 1.0, 26th, June, 2017.

[18] JARUS, "Recommendations for Certification Specification for Light Unmanned Aeroplane Systems," Joint Authorities for Rulemaking on Unmanned Systems, Edition: 0.3, 9th, Nov, 2016.

[19] JARUS, "Certification Specification for Light Unmanned Rotorcraft Systems," Joint Authorities for Rulemaking on Unmanned Systems, CS-LURS, Edition: 1.0, 30th, Oct, 2013.

[20] FAA, "Advisory Circular: System Safety Analysis and Assessment for Part 23 Airplanes," Federal Aviation Administration, 17th, Nov, 2011.

[21] EASA, "Certification Specifications and Acceptable Means of Compliance for Large Aeroplanes," European Aviation Safety Agency, Amendment 23, 15th, July, 2019.

[22] FAA, "Advisory Circular: Certification of Normal Category Rotorcraft (27-1B)," Federal Aviation Administration, 29th, June, 2018

[23] FAA, "Advisory Circular: Certification of Normal Category Rotorcraft (29-2C)," Federal Aviation Administration, 2nd, July, 2018.

[24] FAA. "Unmanned Aircraft Systems (UAS)". Federal Aviation Administration, URL: https://www.faa.gov/uas/ [retrieved 30th, April, 2020]

[25] FAA. "49 USC 44809: Exception for limited recreational operations of unmanned aircraft". Federal Aviation Administration, URL: https://uscode.house.gov/view.xhtml?req=granuleid:USC-prelim-title49section44809\&num=0\&edition=prelim [retrieved 14th, May, 2020]

[26] FAA, "Exception for Limited Recreational Operations of Unmanned Aircraft " Federal Aviation Administration, AC 9157B, 31st, May, 2019.

[27] FAA, "Summary of Small Unmanned Aircraft Rule (Part 107)," Federal Aviation Administration, 21st, Jun, 2016. 
[28] FAA, "Advisory Circular: Small Unmanned Aircraft Systems (sUAS)," Federal Aviation Administration, AC 107-2, 21 st, June, 2016.

[29] FAA, "Unmanned Aircraft Systems Safety Risk Management Policy," Federal Aviation Administration, ORDER 8040.6, 4th, Oct. 2019.

[30] FAA, "Safety Riks Mangement Policy," Federal Aviation Administration, ORDER 8040.4B, 2nd, May, 2017.

[31] FAA, "FAA Safety Management System Manual," Federal Aviation Administration Air Traffic Organization, April, 2019.

"Certification". $\quad$ Federal

Aviation

Administration,

URL: https://www.faa.gov/uas/advanced operations/certification/ [retrieved 19th, November, 2018]

[33] FAA. "Part $107 \quad$ Waivers". Federal Aviation Administration, URL: https://www.faa.gov/uas/commercial_operators/part_107_waivers/ [retrieved 1st. August. 2019]

[34] FAA. "Special Authority for Certain Unmanned Aircraft Systems (Section 44807)". Federal Aviation Administration, URL: https://www.faa.gov/uas/advanced operations/section 333/ [retrieved 12th, May, 2020]

[35] JARUS, "Scoping Paper to AMC RPAS.1309: Safety Assessment of Remotely Piloted Aircraft Systems," Joint Authorities for Rulemaking of Unmanned Systems, Issue: 2, Nov, 2015. 